\title{
Efectos poéticos en "Elegy Written in a Country Churchyard" de Thomas Gray
}

\author{
(Poetic effects in Thomas Gray’s “Elegy Written \\ in a Country Churchyard")
}

ROSALÍA VILLA JIMÉNEZ rosalievj1212@gmail.com

Universidad de Córdoba

Fecha de recepción: 12 de agosto de 2014

Fecha de aceptación: 1 de noviembre de 2014

Resumen: El objetivo que perseguimos en este trabajo es recalar en algunos aspectos de la obra poética del inglés Thomas Gray, tratando de interpretarlos a la luz de las propuestas de la comunicación cognitiva de Sperber y Wilson $(1986 ; 1995)$ y su principio de Relevancia, que fue aplicado al campo de la traducción por Ernst-August Gutt $(1991 ; 2005)$. Tal perspectiva pretende explicar el fenómeno de la traducción como un ejemplo de «semejanza interpretativa» en el traslado interlingüístico de un mensaje determinado, ejemplo de comunicación ostensiva inferencial.

De forma más concreta, tratamos de dilucidar los recursos interpretativos cognitivos que se ponen en funcionamiento en el instante en el que el traductor, primero como receptor del texto original y luego como emisor del texto traducido, transmite toda la información -mismas proposiciones y semejantes implicaciones contextuales- de los textos literarios originales. La información importante para el lector de poesía se transmite, de hecho, por medio de los llamados "efectos poéticos» (Pilkington, 2000).

Palabras clave: Comunicación ostensiva, Inferencia, Implicatura, Efectos poéticos.

Abstract: The aim of this paper is to examine certain passages of the poetic work of Thomas Gray, attempting an interpretation in the light of the cognitive proposal developed by Sperber and Wilson (1986; 1995) and their principle of relevance, applied to the field of translation by Ernst-August Gutt (1991; 2005). This perspective attempts at accounting for the phenomenon of translation as an example of interpretive resemblance in the interlinguistic 
exchange between any two languages, an instance of inferential ostensive communication.

More specifically, we seek to account for the interpretive resources set in action while the translator, first as a receptor of the original text and then as a communicator of the translated text, puts all the information across same propositions and resembling contextual implications- purported by the literary texts. Quite important information, in fact, for the reader of poetry is conveyed through the so-called "poetic effects" (Pilkington, 2000).

Key words: ostensive communication, poetic effects, inference, implicature.

\section{1. "ElEGy WRITTEN IN A COUNTRY CHURCHYARD" (1751) DE THOMAS GRAY}

El célebre poema del reconocido poeta inglés Thomas Gray, "Elegy Written in a Country Churchyard", probablemente se comienza a pergeñar en torno a 1742 y, lo que es un dato más seguro, sale a la luz en 1751 en la revista Pall Mall.

Su visita al cementerio de Stoke Poges, en Buckinghamshire, lugar para la melancólica meditación, aviva la imaginación del poeta, que plasma su sombría percepción del microcosmos social en la enjundiosa creación "An Elegy Written in a Country Church-yard". Este poema glorifica su reputación y rescata la tradición estética de "landscape poetry, the funeral elegy, and the graveyard poetry" (Black, 2011: 1542) ${ }^{1}$. Tras su posterior publicación en 1751, gracias al poeta Robert Dodsley, y su éxito fulgurante, Thomas Gray descollaría en la que se denominaría «Poesía de las tumbas» - Graveyard School en la primera mitad del siglo XVIII.

En líneas generales, el género elegíaco que Gray plasma en "Elegy Written in a Country Churchyard" se enmarca en una época de transición conocida como Prerromanticismo, que atesora una variada gama de estéticas poéticas. Este poema, en concreto, cuenta con las siguientes vetas temáticas, que lo clasifican como perteneciente a la citada Poesía de las tumbas. Estas se acentúan por una melancolía negra, espéculo de la crítica a la vanagloria de la clase pudiente, la realeza y el clero: la miseria del hombre, el timor mortis puritano, la brevedad y la banalidad de la existencia, así como la fusión entre la verosimilitud, el didactismo y el credo religioso con el objeto de insuflar en el lector el sentimiento de

1 "The Manor House of Stoke Poges in Buckinghamshire lies in the ancient village called Stoches, recorded in the Domesday Book in 1086, and held at a later stage by William of Stoke. Two hundred years after William, Amicia of Stoke, heiress of the occupant of the Manor, married Robert Pogeys, who was Knight of the Shire. Hence, the complete name. Th. Gray, buried in the local churchyard of St Giles', described the house in the poem "A Long Story" (Cf. Villa-Jiménez, Rosalía and Vicente López-Folgado, "Don Juan de Escóiquiz's Spanish version of Gray's "Elegy Written in a Country Churchyard." En: Ma Mar Rivas \& Carmen Balbuena (eds.). Cultural Aspects of Translation. Tübingen: Narr Verlag, 2013, pp. 237-256). 
arrepentimiento y la reflexión sobre el Juicio Final, la condena eterna y la salvación espiritual. Las acciones del hombre en el viaje de la vida serán juzgadas por un Juez justo: Gray enaltece al eslabón marginado de la sociedad por su nobleza, mientras que critica a la cúspide social por su actuación egoísta y su férreo apego a la privatización del bien común.

El epitafio o requiem universal se entiende como la parte reflexiva y moral en la que Gray se sumerge en meditaciones de índole religiosa: la muerte, el Juicio Final, la condena eterna o la salvación del alma, de modo que se castiga lo material y antepone la creencia religiosa como el cénit del entendimiento entre el microcosmos del hombre y el macrocosmos del poder divino.

"Elegy Written in a Country Churchyard" refleja, asimismo, la aparición de nuevas corrientes ideológicas que abrazan el escepticismo y el subjetivismo frente a la ortodoxia puritana heredada del siglo XVII. Es manifiesto, de igual modo, el temor y subsecuente búsqueda del orden tras un largo período de inestabilidad con las contiendas político-religiosas de la Restauración que estallan en la Revolución Gloriosa de 1688.

Tras la instauración de la Casa de Hanover y el reinado de Jorge I y Jorge II, la nación inglesa disfruta de la estabilidad tan anhelada después del nefasto gobierno de la reina Ana a principios del siglo XVIII. No obstante, la brecha entre las clases sociales se acentúa, lo que desplaza a la clase obrero-artesanal hacia un declive más profundo que en siglos precedentes. Tales circunstancias históricas provocarán el sentimiento de empatía del que habla Adam Smith o el Conde de Shaftesbury y que se evidencia en el culto a la sensibilidad en la época un tanto oscura y de transición Ilamada Prerromanticismo - que abarca desde 1750 a 1798 aproximadamente $-{ }^{2}$ y a la que pertenece el poeta objeto de este estudio.

En lo que respecta a la estructuración formal, la elegía de Gray tiene una disposición versal regular de 32 cuartetos, entre los cuales se distingue el epitafio (las tres últimas estrofas). Los versos presentan un esquema de rima alternante (ABAB). Se aprecia una rima consonante idéntica a lo largo de la serie de cuartetos que genera un efecto de completitud y perfección, verbigracia:

Now fades the glimmering landscape on the sight, /sart /

And all the air a solemn stillness holds, /houldz /

Save where the beetle wheels his droning flight, /flart /

\footnotetext{
${ }^{2}$ Northrop Fry. "Towards Defining an Age of Sensibility." He argued there: Our students are thus graduated with a vague notion that the age of sensibility was the time when poetry moved from a reptilian Classicism, all cold and dry reason, to a mammalian Romanticism, all warm and wet feeling" (Fry, 1955: 144).
} 
And drowsy tinklings lull the distante folds. /fouldz /

(Th. Gray, "Elegy Written in a Country Churchyard", vv. 5-8)

Atingente al ritmo, el patrón matriz rítmico del poema es el pentámetro yámbico (cinco pies yámbicos con alternancia de una sílaba no acentuada y otra acentuada), como se desprende de este ejemplo:

The lo | wing herd | winds slow | ly o'er | the lea;

En lo que al tipo de estrofa se refiere, "Elegy Written in a Country Churchyard" se trata de una elegía compuesta por 128 versos de arte mayor, decasílabos en su mayoría (que al acabar en sílaba aguda equivaldrían a versos eneasílabos).

\section{EL MENSAJE IMPLÍCITO EN LOS TEXTOS LITERARIOS}

Roman Ingarden (1973) señala que la obra literaria, independientemente del género en el que se enmarque, comprende cuatro estructuras o estratos básicos, construidos de forma intencionada, que juegan un papel esencial en el descubrimiento por parte del lector de la(s) única(s) interpretación(es) del autor, es decir, de la información implícita. Deslinda, así, 1) el nivel fonético; 2) el nivel semántico de la oración o conjunto de oraciones; 3 ) el nivel en el que las intenciones y los objetos de la realidad ficticia se muestran y 4) el nivel en el que dichas intenciones y los objetos ficticios se materializan mediante la oración u oraciones (el autor insufla sus intenciones en el texto deliberadamente para que el lector las infiera), aunque siempre existe la posibilidad de que la multiplicidad de sucesos, objetos e intenciones excedan la representación oracional, lo que da lugar a los denominados places of indeterminacy (Ingarden, 1973: 12 13). De igual manera, distingue dos tipos de valores, el artístico y el estético, que revelan una verdad acerca del autor o determinados valores sociales, culturales o religiosos de una época concreta.

En lo relativo al valor artístico, este se concibe como el andamiaje del mundo representado del texto literario que permite la atribución de las experiencias, así como la imposición de la concepción de lo real del lector. Concerniente al valor estético, este se expresa mediante la experiencia estética de lo bello, lo agradable, y depende de las vivencias de los sujetos (autor / lector) (Vergara, 2002: 6-7) . $^{3}$

\footnotetext{
${ }^{3}$ Estos valores están presentes en los cuatro planos anteriores y los que, según Zhonggang, forman parte de los efectos cognitivos del texto literario, "my notion of contextual effects can be presented: the contextual effects that a literary text yields can be analyzed in three layers: artistic, aesthetic and informative layers" (Zhonggang, 2006: 52). De forma análoga, las pistas
} 
Como parte de la comunicación humana que se fundamenta en el proceso cognitivo de la inferencia en la que predomina la explotación de la información implícita, es reseñable decir que los textos literarios se caracterizan por un uso ostensivo y cuidado del lenguaje por parte del autor de una obra, "containing implicit information" (Zhonggang, 2006: 43), enmarcado en el esquema general de las convenciones de un género literario, lo que le permite al autor transmitir un rico abanico de ideas, sentimientos e impresiones que no se presentan necesariamente de forma explícita: "To communicate a richness of ideas, feelings and impressions that are not necessarily expressed in words, but communicated implicitly" (Gutt, 1996: 241).

Este género de textos está cargado de información implícita que sigue formando parte de "the total communication intended or assumed by the writer" (Larson, 1984: 38). El autor de un texto literario se sirve de los recursos lingüísticos para obtener determinados efectos y establecer "a working cooperation with [his] audiences" (Mey, 2010: 12). En otros términos, las particularidades y características que conforman los textos literarios, tales como la ambigüedad, la connotación, la polisemia (significados múltiples) y la transmisión de una gama ilimitada de ideas e imágenes que ofrecen un panorama físico y metafísico del mundo. Ya que este tipo de textos posee una reserva de interpretaciones indeterminada, el lector requiere un mayor esfuerzo cognitivo inferencial para discriminar entre sus suposiciones cognitivas y llegar a las más relevantes; lograr, por ende, la síntesis entre su contexto cognitivo y el del comunicador, es decir, descubrir la interpretación que el texto del autor implica se convierte en un paso de cierta dificultad.

Sperber y Wilson $(1986 ; 1995)$ describen el estilo, extensivo a todo uso de la lengua pero que atañe a los textos literarios en este apartado (estilo literario), como un concepto relacional, cuya elección y función están restringidas a la búsqueda de la Relevancia óptima, en la que la forma lingüística del enunciado es el vehículo canalizador de dicha relación: "La relación se establece, por tanto, entre el emisor y su intención comunicativa, (...) y el destinatario y sus capacidades interpretativas" (Escandell, 1994: 56).

comunicativas, referidas como las propiedades estilísticas y textuales, para Zhonggang incluyen las cuatro estructuras principales y los dos valores del texto literario, los cuales el traductor debe compartir en el texto meta en concordancia con el principio cognitivo de Relevancia para lograr la semejanza interpretativa.

4 This is called in cognitive terms the communicative principle of the "presumption of relevance" (Sperber and Wilson, 145: 1990). 
Puesto que la manifestación del estilo más comúnmente admitida es la figura literaria y ya que esta supone un mayor esfuerzo cognitivo para procesarse, es crucial que el emisor aporte suficientes efectos cognitivos para que el receptor alcance la interpretación más relevante evocada con la figura discursiva con el mínimo de coste posible y el máximo de beneficio. En efecto, el género literario es un factor importante que obliga, a la vez que ayuda al lector a limitar el contexto de sus suposiciones. Por consiguiente, el emisor debe hacer que el esfuerzo realizado por parte del lector sea recompensado con «unos efectos cognitivos suficientes, de modo que el balance coste / beneficio siga siendo positivo" (Escandell, 1994: 58), de modo que se ajuste, así, a la presunción de la Relevancia óptima y a la feliz interpretación de los enunciados para que las suposiciones cognitivas y las conclusiones obtenidas por el receptor empasten perfectamente con las del emisor, lo que derivaría en implicaturas fuertes y en una comunicación productiva:

\footnotetext{
Se llaman así porque son imprescindibles para la correcta interpretación del enunciado y porque el emisor resulta ser directamente responsable de su veracidad: las ha calculado y espera que su interlocutor recupere exactamente esas premisas, y no otras; y que obtenga esas conclusiones, y no otras. (Escandell, 1994: 59).
}

Por el contrario, las implicaturas débiles posibilitan un amplio repertorio de interpretaciones aceptables que no están predeterminadas por el emisor, sino que aparecen solo a cargo del lector, quien las explora, y que pueden o no concurrir con las expresadas implícitamente en el texto. De estas trascendienden los designados efectos poéticos: "The peculiar effect of an utterance which achieves most of its relevance through a wide array of weak implicatures" (Sperber and Wilson, 1995: 222).

Un ejemplo ilustrativo de esta clase de efectos son las tradicionales figuras literarias, que contribuyen de forma particular a la interpretación con verdadero contenido (con apariencia de impresiones compartidas) y no con mero valor retórico-ornamental. De esto se deduce la siguiente máxima: cuanto más implicaturas débiles acumule el receptor, y cuanto más débiles sean estas, mayor efecto poético se desprende de la figura del discurso. Por ejemplo, la metáfora obliga al lector a asumir su responsabilidad en virtud de la plétora de interpretaciones que se derivan de este recurso. Los efectos cognitivos aportados debilitan las suposiciones cognitivas del contexto del destinatario y las posibles conclusiones, lo que difumina los contextos compartidos, "la gama de implicaturas no está predeterminada ni limitada, de modo que puede ser extraordinariamente rica» (Escandell, 1994: 59). En la misma vertiente, Sperber y Wilson explican el proceso de esta forma: 
The wider the range of potential implicatures and the greater the hearer's responsibility for constructing them, the more poetic the effect, the more creative the metaphor. A good creative metaphor is precisely one in which a variety of contextual effects can be retained and understood as weakly implicated by the speaker. In the richest and most successful cases, the hearer or reader can go beyond just exploring the immediate context and the entries for concepts involved in it, accessing a wide area of knowledge, adding metaphors of his own as interpretations of possible developments he is not ready to go into, and getting more and more very weak implicatures, with suggestions for still further processing. The result is a quite complex picture, for which the hearer has to take large part of the responsibility, but the discovery of which has been triggered by the writer. The surprise or beauty of a successful creative metaphor lies in this condensation, in the fact that a single expression which has itself been loosely used will determine a very wide range of acceptable weak implicatures. (Sperber and Wilson, 1995: 236-237).

Dada la compleja naturaleza de los textos literarios, el traductor debe ser consciente de las dificultades, entre las que entran en juego las diferencias lingüísticas y culturales, que supone traducir la información implícita del texto de partida al de llegada. Como acto específico de comunicación interlingüística, y al igual que la producción de cualquier tipo de texto (oral y escrito) de cualquier género, la traducción de textos literarios obedece, asimismo, al principio de Relevancia, por medio del cual el mensaje del emisor / traductor llega a ser debidamente descodificado por el destinatario / lector, que se convierte en un factor fundamental al que el traductor debe tener siempre presente, y sobre todo, cuando traduce información implícita encriptada en el texto origen: "the translator is the reader, but interprets a text for yet another interpreter" (Dahlgren, 2005: 1105).

Gutt (2000) subraya que el factor trascendental es que "the target audience can arrive at the intended meaning through consistency with the principle of relevance" (Gutt, 2000: 251), por lo que incurre en la máxima de que la Relevancia depende obligatoriamente de los contextos del autor, del traductor y del lector. El texto meta debe provocar suficientes efectos cognitivos en las suposiciones contextuales del lector de la lengua de llegada para que el mensaje implícito del autor sea accesible. Por tanto, el mensaje ha de ransmitirse e interpretarse con el mínimo esfuerzo: "the translation communicates successfully when the target audience recognises what the translator intended to communicate [of the original]" (Gutt, 2000: 251).

La tarea del traductor en el proceso traslativo como acto comunicativo secundario (TO-traductor / comunicador-lector meta), en el que "the 
communication in which the addresse [TT] does not have access to the original communicator's context" (Zhonggang, 2006: 54), es suplir al receptor del texto meta de suficientes efectos cognitivos para procesar la información implícita, ya que el lector del texto meta se verá obligado a emplear un gran esfuerzo hasta alcanzar las suposiciones contextuales del emisor del texto fuente debido a la distancia lingüística y cultural, además de la diferencia entre los contextos cognitivos del autor y del receptor.

La traducción es un paradigma de comunicación ostensiva (inferencial) entre dos lenguas y culturas diferentes. Esta se clasifica en traducción directa e indirecta, ejemplo del uso interpretativo de la lengua. Mientras que la traducción directa conlleva semejanza interpretativa (completa) de las suposiciones cognitivas y pistas comunicativas (propiedades textuales, estilísticas y efectos) del texto origen, la indirecta supone presunción de fidelidad y semejanza interpretativa (parcial). Por consiguiente, en la traducción de textos literarios existe la posibilidad de: primero compartir las mismas pistas comunicativas y suposiciones cognitivas del texto origen, lo que puede derivar en la pérdida o debilitación de Relevancia, y en una interpretación incorrecta del mensaje original, bien por las barreras lingüístico-culturales, o bien por la disparidad entre contextos cognitivos; y segundo, hallar la semejanza interpretativa en relación al principio cognitivo de Relevancia.

La traducción indirecta es la opción preferible en la traducción de textos literarios, dado que ofrece la posibilidad de modificar las pistas (clues) comunicativas en el texto meta con el fin de establecer la comunicación efectiva entre el texto de llegada y el destinatario de la lengua meta. Asimismo, el traductor debe prestar máxima atención a la semejanza interpretativa, a la presunción de fidelidad con respecto al texto origen y a las expectativas del lector meta. En otras palabras, el traductor debe hacer que el texto traducido sea tan relevante como el texto original. Esto se debe efectuar en consonancia con el principio cognitivo de Relevancia, de modo que a mayores efectos cognitivos, menor resultará el esfuerzo realizado por el lector meta para procesar la información implícita.

\section{EL CONCEPTO DE RELEVANCIA EN LA TRADUCCIÓN}

En lo concerniente a la traducción, Ernst-August Gutt (1991) sugiere un enfoque con base en la Teoría de la Relevancia de Sperber y Wilson (1986; 1995) para explicar el fenómeno de trasladar un mensaje determinado de una lengua a otra. La suposición crucial, y premisa en torno a la que gira esta aproximación cognitiva, es que la traducción es un vehículo de comunicación que no se concibe en el sentido tradicional, tan repetido entre los modelos funcionalistas, de codificación-descodificación de la información lingüística en el enunciado, sino que se entiende como una 
manifestación de comunicación ostensiva (inferencial) que va más allá del código lingüístico, a la vez que se explica satisfactoriamente con el concepto de comunicación secundaria ${ }^{5}$.

Referente a la labor del traductor, este se convierte en comunicador cuando el estímulo en la lengua meta no se presenta "in its own right, but as a representation of an original source language stimulus" (Gutt, 1991: 79), de modo que crea un estímulo ostensivo verbal que proyecta el original de la lengua origen lo más fielmente posible a las suposiciones contextuales relevantes originales con el fin de hacerlas llegar al destinatario de la lengua meta.

En cuanto al axioma de que toda traducción ha de transferir la información del texto original, Nida y Taber (1969) adujeron hace ya tiempo su noción de equivalencia dinámica: "Translating must aim primarily at 'reproducing the message'. To do anything else is essentially false to one's task as a translator" (Nida and Taber, 1969: 12). Gutt (1991), no obstante, aborda este argumento de la siguiente manera: en lo relativo al trasvase del mensaje original, las suposiciones de Relevancia óptima del texto de partida (estímulo ostensivo verbal) que se transmiten en forma de explicaturas e implicaturas dependen del contexto que, esencialmente, debe ser compartido por el traductor y el comunicador de la lengua de origen. Por el contrario, si un estímulo ostensivo verbal se interpreta en un contexto cognitivo que difiere del contexto del comunicador de la lengua de origen, el resultado indefectiblemente será problemático, o como lo exspresa Gutt "misunderstanding is likely to arise" (1991: 80).

De forma similar, para que la comunicación de la interpretación del texto meta se efectúe, no solo es tarea del traductor reproducir las mismas explicaturas e implicaturas, sino además debe adecuar el proceso inferencial a cargo del receptor al principio cognitivo de Relevancia, por lo que las suposiciones cognitivas son las óptimamente relevantes y las que, de hecho, producen un mayor número de efectos cognitivos. Es preciso decir a este respecto que, la traducción no solo se contempla como una manifestación de comunicación ostensiva (inferencial), sino que además se define como paradigma del uso interpretativo de la lengua, siguiendo los axiomas de la Teoría de la Relevancia, tanto en lo que se denomina traducción directa e indirecta, puesto que mediante ambas el traductor

\footnotetext{
5 Para Gutt, (1991) la traducción es un uso interpretativo de la lengua y un proceso interlingüístico en el que las suposiciones cognitivas o intenciones que el comunicador original expresa en la LO se trasvasan a la LM gracias a la intervención del traductor. Esta noción, que está ya en la obra de Sperber y Wilson $(1986 ; 1995)$, es la que posibilita una definición común a cualquier tipo de traducción, "Since this is true of all forms of translation, the notion of interpretive use provides the common denominator that enables Gutt to offer a unified account of translation" (Smith, 2002: 109).
} 
pretende transmitir la interpretación o significado del texto fuente y del comunicador.

Según Sperber y Wilson (1986; 1995), todo estímulo verbal y no verbal es una representación de una situación o "state of affairs" (de algún fenómeno del mundo real del que se producen proposiciones de verdad o falsedad) entre los que existe un alto grado de semejanza. Por el contrario, los enunciados no son meras "representations in virtue of representing some [physical] phenomenon" (Sperber and Wilson, 1995: 227), sino que representan otros determinados enunciados formulados por otro hablante al que necesariamente se asemejan, "It resembles that utterance because it is a token of the same sentence: it is a direct quotation [direct speech]" (Sperber and Wilson, 1995: 227). Esta concepción se deriva en el estilo directo de la lengua, en el que se transmiten las estructuras lingüísticas y semánticas, es decir, las mismas proposiciones (el contenido lógicosemántico) de las oraciones de los enunciados de los hablantes. De esto se puede coligir un uso descriptivo de la lengua: "A language utterance is said to be used descriptively when it is intended to be a taken as true of a state of affairs in some possible world" (Gutt, 1998: 44). Dicho de otra manera, es propio del uso descriptivo que se reproduzcan los pensamientos del hablante con los que se pretende representar la realidad, "someone speaking descriptively intends to be faithful to reality" (Smith, 2002: 108).

De este uso descriptivo de la lengua se origina la traducción directa, que se concibe como un estímulo verbal de la lengua de llegada que tan solo debe crear, "a presumption of complete interpretive resemblance with the source language original" (Gutt, 1989: 88). Sin embargo, en la traducción directa es imprescindible que el traductor, en primera instancia, capte la interpretación o suposiciones contextuales del texto origen para garantizar la semejanza interpretativa (completa) entre el texto fuente y el texto de llegada para que la comunicación sea efectiva, lo que la distingue del estilo indirecto de la lengua que, en efecto, puede realizarse sin una perfecta comprensión de la interpretación implicada por el comunicador original, "simply by producing another token of the same sentence type" (Gutt, 1990: 142).

Otro factor concerniente a la traducción directa es que el lector meta recupera la interpretación implicada originaria o suposición cognitiva en el texto original, de modo que debe familiarizarse con el contexto cognitivo del autor sin tener al traductor como comunicador, sino al emisor original como transmisor de sus suposiciones cognitivas. Es imprescindible, pues, en la interpretación literaria, que el lector meta tenga en cuenta el hecho de que la interpretación o suposiciones cognitivas de un texto literario original son una reconstrucción "of the historical, cultural and sociological background against which that piece of literarute was created" (Gutt, 1989: 15). Debido a 
que con este tipo de traducción la intención es conseguir la semejanza interpretativa (completa) con respecto al texto fuente, los contextos cognitivos del receptor y del comunicador del texto de partida deben coincidir.

En lo que atañe al traductor, al no intervenir, la traducción directa del estímulo ostensivo verbal no impedirá que el receptor naufrague en un contexto y suposiciones cognitivas que difieren de las del comunicador original. Para hacer que el receptor del estímulo meta concilie con las suposiciones cognitivas del texto origen, la traducción no solo debe hacer manifiesto las mismas explicaturas e implicaturas y el mismo efecto del original, sino que además debe hacerlas evidentes mediantes las mismas pistas comunicativas del estímulo ostensivo verbal original (enunciado / texto).

Las pistas (clues) comunicativas se entienden como las propiedades textuales y estilísticas particulares del TO (propiedades semánticas, sintácticas y fonéticas, la onomatopeya, 0 propiedades poéticas y expresiones idiomáticas, etc.) que guían las inferencias del receptor para lograr la interpretación implicada por el comunicador, quien establece una serie de propiedades textuales que dirijan al lector "to the intended interpretation" (Gutt, 2000: 161). Mas considerando que la traducción es un ejemplo de comunicación interlingüística, se denominan pistas comunicativas no solo a las propiedades textuales y estilísticas del TO, sino también al hecho de que deben tener un efecto similar tanto en el texto origen como en el texto meta, que hacen que el escritor original y el lector meta compartan, por tanto, el mismo contexto cognitivo, del que se origina la resolución de la interpretación implicada del emisor del texto origen: "When they are mutually manifest in both cognitive contexts which will help the audience to arrive at the intended interpretation. (Gutt, 2000: 161) ${ }^{6}$.

No obstante, el acto comunicativo ostensivo se sucede entre dos lenguas distintas, por lo que en gran número de ocasiones, el trasvase de las pistas comunicativas de una lengua de partida no puede efectuarse de forma exacta. Para salvar este obstáculo, el traductor debe lanzarse a la búsqueda de propiedades textuales que manifiesten efectos cognitivos

\footnotetext{
${ }^{6}$ A su vez, estas se deben considerar según lo que se pretende comunicar en el texto origen y lo que el traductor comunica mediante el texto meta. Según Gutt (2000), el hecho de mantener las mismas pistas (en inglés clues) comunicativas del texto fuente puede derivar en un mayor esfuerzo a cargo del traductor y del receptor del texto de llegada, puesto que se puede llegar al trasvase de expresiones idiomáticas no naturales en la lengua meta (en particular, esto es evidente en la traducción directa), "the reformulated communicative clues must be natural to the idiom of the receptor language" (Smith, 2002: 11). Por tanto, Gutt sugiere que "communicative clues cannot be used in translation in any mechanical way. It requires a good understanding of the inferential nature of communication" (Gutt, 2000: 170).
} 
semejantes en las dos lenguas. En consecuencia, tal operación se resolverá en la buscada semejanza interpretativa completa:

The situation changes when considering cross-lingual communication, and this is where it seemed helpful to form a more abstract concept than the textual property. The reason is that languages differ in the inventory of linguistic features or properties they have; hence property $A$ of language $X$ may simply not be found in language $Y$. Nevertheless one can very often find some means $B$ in language $Y$ that achieves the same or at least similar effect as property $A$ did in language $X$, assuming identical contexts. Properties that can be linked in this way are referred to as corresponding "communicative clues". (Gutt, 2000: 163).

Si en la comunicación ostensiva (inferencial) intervienen dos lenguas distintas, debemos poner en tela de juicio la eficacia de la traducción directa para transmitir el mensaje. Las diferencias lingüísticas entre el texto origen y el texto meta son un óbice para alcanzar una semejanza interpretativa completa, ya que las interpretaciones a las que llega el lector meta por medio de la traducción tienden a diferir no solo de las del lector original, sino del contexto del comunicador. De forma semejante, este tipo de traducción normalmente incurre en el empleo de expresiones lingüísticas que en la lengua meta no tienen cabida, lo que conlleva una probable mala interpretación del mensaje.

Existe la posibilidad, por otra parte, de preservar la semejanza entre enunciados, a pesar de poseer distintas proposiciones, lo que se traduce como estilo indirecto, "the only generally acknowledged interpretive use of utterances is the reporting speech or thought" (Sperber and Wilson, 1991: 229) y como uso interpretativo de la lengua, "an utterance is said to be used interpretively when it is intended to represent what someone said or thought" (Gutt, 2000: 170) o, tal como Sperber y Wilson apuntan, "every utterance is used to represent a thought of the speaker's" (Sperber and Wilson, 1991: 230). Igualmente, Smith (2002) indica que el interlocutor pretende ser fiel "to the meaning of the original speaker" (Smith, 2002: 108). Por tanto, un texto 0 un enunciado con el que se pretende representar el pensamiento (representación de suposiciones cognitivas) del comunicador se clasifica como expresión interpretativa de la que el receptor deriva suposiciones cognitivas interpretativas que se asemejan (resemble) a las del emisor original (López-Folgado, 2010: 62).

De este uso interpretativo de la lengua se despliega la traducción indirecta, en la que dos textos o dos enunciados manifiestan presunción de fidelidad, noción que nace de la semejanza interpretativa y del principio cognitivo de Relevancia. El traductor, como comunicador, crea la presunción 
de que la interpretación o suposiciones cognitivas que pretende transmitir en el texto meta se asemejan a las suposiciones originales, es decir, tiene la finalidad de vertir la interpretación original "that he believes to be adequately relevant" (Gutt, 1990: 142). Esto significa que el núcleo de la traducción indirecta es maximizar la Relevancia, de comunicar los suficientes efectos cognitivos para minimizar el esfuerzo que se espera del receptor para llegar a la interpretación implicada. En este caso, la labor del traductor es considerar las suposiciones cognitivas del receptor del texto meta, que servirán de anclaje para llegar a las suposiciones cognitivas del texto fuente.

Sin embargo, se debe tener en cuenta el hecho de que intervienen dos códigos lingüísticos que divergen entre sí para efectuar el proceso de traslación:

As an instance of interpretive use, an indirect quotation is used in virtue of its interpretive resemblance with the original; by the principle of relevance it creates a presumption that the interpretation offered will be adequately relevant under optimal processing. (Gutt, 1991: 87).

Debido a las diferencias lingüísticas y cognitivo-contextuales tanto del emisor original, del traductor / comunicador y del receptor del texto meta, para lograr la mencionada semejanza interpretativa y la presunción de fidelidad, el traductor debe hacer manifiestos semejantes las propiedades y los efectos (a lo que se denomina pistas comunicativas, como se ha ilustrado anteriormente) del estímulo ostensivo verbal (enunciado / texto meta). Con la modificación de las propiedades textuales, estilísticas y efectos del texto original al pasar al texto meta se tratará de conseguir que la comunicación sea efectiva. De este modo, se produce un trasvase apropiado, aunque no con el mismo grado de semejanza, como ocurre con las pistas comunicativas de la traducción directa, en las explicaturas y aún menos en las implicaturas. El traductor como emisor, teniendo en cuenta el contexto cognitivo del receptor, comunica aquellas suposiciones cognitivas o interpretaciones del texto de partida que considere más relevantes y accesibles, de manera que el lector meta pueda recuperarlas apropiadamente en conjunción con el principio cognitivo de Relevancia.

Las ideas principales de la traducción directa e indirecta, cuya finalidad es que la comunicación del mensaje, interpretación o intenciones del comunicador del texto fuente sea efectiva, se sintetizan en el siguiente párrafo:

A receptor language text presented as an indirect translation would be processed on minimal assumptions about resemblance, i.e. on the assumption that the translation resembled the principle of relevance. By contrast, a direct translation would be processed on maximal 
assumptions about resemblance in view of the presumption of complete interpretive resemblance. (Gutt, 1991: 90).

\section{INTERPRETACIÓN DE "ELEGY WRITTEN IN A COUNTRY CHURCHYARD"}

Ernst-August Gutt (1991) aborda el fenómeno de trasvasar de una lengua a otra la información implícita (o interpretación de un texto) como un proceso cognitivo, como un acto de comunicación secundaria ostensiva e inferencial. En este procesamiento mental y en la traslación del mensaje de un texto origen a un texto meta entra en juego el traductor como lector meta y comunicador de la interpretación implicada por el autor original: "El pensamiento no lo revestimos con palabras. Hay siempre una brecha entre lo que las palabras significan y lo que comunican en el contexto concreto del poema" (López-Folgado, 2013: 95).

En la traducción de "Elegy Written in a Country Churchyard", paradigma de la traducción indirecta, tal y como la concibe Gutt, nos centramos en presentar el mensaje del texto origen implicado en los enunciados del poema en términos de semejanza interpretativa, teniendo en cuenta la realidad mental del autor y la del lector de la traducción, de modo que se cumpla el principio cognitivo de Relevancia y se logre su grado de optimización.

Con una estructura regular a lo largo del poema original, en la que se observa una constante alternancia entre pasajes descriptivos y meditativos, los versos que constituyen el primer cuarteto se enmarcan en el corpus de descripciones realistas y naturalistas, dada la serie de pistas comunicativas que el autor emplea, tales como la retórica poética propia del género y el contexto en el que el poeta se encuadra.

En relación a estas, como preludio al epitafio que concluye el conjunto de meditaciones, Gray selecciona sintagmas nominales y adjetivales que merman el efecto cognitivo de movimiento y que se adecuan perfectamente al efecto estático del instante de descripción visual y sonora del ocaso, que anuncia el retiro en la oscuridad de la noche. La elección del pentámetro yámbico, con cierto valor icónico, revela el cuadro que introduce al lector en un ambiente cargado de descripciones sensoriales, en el que el sonido del tañido de la campana, o más bien el mensaje que anuncia, se hace eco de la melancolía del paisaje sereno.

La secuencia descriptiva ofrece el marco rural idóneo para manifestar la lentitud del paso del tiempo, la tristeza y la soledad. Asimismo, proporciona la fusión entre la Naturaleza en su movimiento cíclico y los personajes anónimos o aldeanos que beben del organicismo del universo:

The lowing herd winds slowly o'er the lea; 
The ploughman homeward plods his weary way,

And leaves the world to darkness and to me

(Th. Gray. "Elegy Written in a Country Churchyard", vv. 1-4)

Para el análisis cognitivo de la estrofa que nos atañe, se ha considerado imprescindible seguir las mismas pautas que en el texto original de Gray con el objeto de reflejar el efecto de serenidad y de silencio que domina y enriquece al cuarteto. Para ello, se han reproducido pistas comunicativas análogas a las de "Elegy Written in a Country Churchyard". Predomina, en general, una sintaxis nominal en la que los verbos están sujetos al descanso y son cómplices del tono melancólico de la soledad que emana de los sintagmas que hacen alusión al atardecer.

La traducción propuesta para este cuarteto, sin embargo, adolece de la exclusión del paralelismo y del ritmo yámbico del poema inglés, que ponen de relieve el silencio y el descanso del paraje natural, ya que el patrón métrico por excelencia que se ha seguido, el alejandrino, presenta determinadas restricciones:

1a) The Curfew tolls the knell of parting day;

1b) El doblar de campanas suena triste al ocaso;

En el poema original se aprecia una latente aliteración en los versos 1 y 2 (la consonante líquida 'I' de tolls, knell, lowly y slowly), pista

${ }^{7}$ Thomas Gray, fiel seguidor del poeta italiano Dante Alighieri, recoge en el v. 1 de su "Elegy Written in a Country Churchyard" los vv. 5-6, "se ode squilla di Iontano / che paia "I giorno pianger che si more" (The Vesper bell, that mourns the dying day / si oye a lo lejos alguna campana / que parezca plañir al moribundo día) del «Purgatorio», Canto VIII, de la célebre Divina Comedia. Ambos poetas describen la hora del ocaso, vislumbrándose la costumbre religiosa cristiana de que el atardecer es el adviento de la noche y del retiro a la oración para recibir al sol naciente de la mañana, representación de Jesucristo y la salvación, (Trad. Ichabod, 1845: 74). Luego, no es mera coincidencia que la secuencia de las cuatro primeras estrofas emanen el tono lúgubre del descanso para contrarrestarse con la llamada alegre del día de la estrofa quinta.

${ }^{8}$ Federico García Lorca (1898-1936), poeta español de la Generación del 27, en su «Canción primaveral» (1919) en Libro de Poemas refleja el aire melancólico y el marco lúgubre de la Naturaleza en los versos siguientes: "Voy camino de la tarde / entre flores de la huerta, / dejando sobre el camino / el agua de mi tristeza. / En el monte solitario, / un cementerio de aldea / parece un campo sembrado / con granos de calaveras. / Y han florecido los cipreses / como gigantes cabezas / que con órbitas vacías / y verdosas cabelleras, / pensativos y dolientes / el horizonte contemplan" (II, vV. 9-22) (García-Lorca, 1996: 83). El tema y el tenor del cementerio se plasma también en la poesía del poeta y filósofo español Miguel de Unamuno y Jugo (1864-1936) de la Generación del 98 en su poema «En otro cementerio de aldea», en el que describe el cementerio del castillo de Arévalo. La gallega Rosalía de Castro (1837-1885), bajo la influencia del gusto por la muerte de los poetas (pre)románticos, en sus Follas Novas (Cementerios de Galicia), publicada en 1880, reflexiona sobre el tópico clásico de la brevedad de la vida con el locus eremus del paisaje gallego. 
comunicativa que contribuye, suponemos, al efecto poético intensificador del adormecimiento del atardecer. Esta figura del discurso poético desaparece en la versión al español, de forma que tal efecto se vierte con lexemas que conllevan el mismo sentido y con los que se transmite idéntico mensaje, «el doblar de campanas», «triste» $\mathrm{y}$ "ocaso».

El lexema curfew («toque de queda» 0 «toque de campana») ${ }^{9}$, junto con el sustantivo knell («doblar o tañido de la campana que anuncia la defunción») y el verbo toll («tañir», «doblar» o «tocar»), que siempre coloca con el referente "campana», se leen como pistas comunicativas de las que se tiene una implicación metafórica al unirse al sintagma parting day. Las campanas que doblan por la defunción de un concepto temporal y cíclico se hacen perceptibles y se humanizan con la imagen de las actividades mundanas. Estas vaticinan el descanso eterno de la vida que aparece en el epitafio final.

A pesar de que se ha elidido el lexema curfew en la traducción, se mantiene el efecto cognitivo de melancolía, de carácter visual y acústico, del original mediante "el doblar de campanas», que se funde con el sentido del toque de queda de las campanas de la tradición anglo-normanda y con el de knell. Asimismo, este "suena» (tol) «triste», adjetivo que subraya la melancolía del toque de campanas y que presagia la muerte «al ocaso» (parting day), lo que augura el atardecer del individuo mencionado en el epitafio, una de las voces poéticas con las que el autor se identifica.

2a) The lowing herd winds slowly o'er the lea;

2b) marcha lento el ganado mugiendo por los prados;

En el siguiente verso, el verbo wind («serpentear»), que se enfatiza con el adverbio slowly y que evoca el avance lento y pausado del ganado vacuno por las sinuosidades del campo, se ha omitido en el texto traducido en aras del metro silábico alejandrino. No obstante, se ha sustituido por el sintagma «marchar lento», que tiene representaciones semejantes.

3a) The ploughman homeward plods his weary way,

$3 b)$ vuelve a casa el labriego con su paso cansino,

\footnotetext{
${ }^{9}$ Viene al caso aclarar que la palabra inglesa curfew proviene de la "francesa 'couvre feu' y se remonta a la época normanda, cuyas leyes ordenaban apagar todos los fuegos al caer la tarde tras un toque de campana para impedir desmanes y alteraciones del orden" (López-Folgado, 2009: 134). De igual modo, Roger Lonsdale señala que el toque de queda, desde Guillermo e Conquistador, seguía sonando en Cambridge hasta la época de Thomas Gray (Lonsdale, 1969: 117).
} 
El núcleo verbal de la oración del verso siguiente, plod («caminar lenta y pesadamente») manifiesta el letargo nostálgico a la hora del crepúsculo. El efecto cognitivo trascendente de andar y la lenta quietud se representa con "con su paso cansino" adscrito al verbo «volver». Se han obviado las aliteraciones en ploughman, homeward (la consonante bilabial sonora ' $m$ ') y de ' $p$ ' en plods y en weary way (la semivocal / semiconsonante doble ' $v$ '), que proveen al verso del efecto lúgubre del atardecer, debido a la inexistencia de un referente en la lengua meta semejante en grafema y fonema al original.

4a) And leaves the world to darkness and to me.

4b) y solo me abandona en medio de tinieblas.

En el último verso, se hace alusión al "yo poético» con el que se enmascara el poeta, que contempla en solitario la esencia decadente del anochecer, así como el dormitar del agridulce alboroto de los quehaceres mundanos de los humildes labriegos. El núcleo de la acción leaves («dejar» o «abandonar» en tercera persona de singular), de forma anafórica, no solo hace alusión al sol que se oculta (parting day), sino también a la manada mugiente (lowing herd) y al campesino que se recoge (ploughman). De este modo, concuerda en número con los sintagmas nominales de sujeto de los dos versos precedentes.

Se ha preferido el lexema «tinieblas» para el lexema inglés darkness («noche», «oscuridad» o «tinieblas»), ya que se considera que el sentido en que ha desembocado la estrofa engloba la apreciación de un entorno físico crepuscular (una tonalidad claro-oscura de una melancolía agridulce), que se va tiñendo de un timbre meditativo con la aparición del me («a mí») de la voz poética, que anticipa la serie meditativa tras la descripción naturalista de este beatus ille ${ }^{10}$. Del mismo modo, se ha prescindido del lexema world («mundo») en la traducción, pero esta omisión, forzada por la estructura métrica, no obstaculiza la transmisión tanto del efecto cognitivo como del mensaje críptico del verso original: se abandona al «yo poético», hipónimo de la clase campesina y del género humano (hiperónimo), a merced de las sombras, lo que vaticina las oscuras reflexiones sobre la muerte que se sucederán en los siguientes cuartetos.

Si bien se han alterado determinadas pistas comunicativas, por el contrario, se ha respetado el principio cognitivo de Relevancia, en el que se han hecho relevantes al lector meta aquellas suposiciones concebidas como óptimamente relevantes (la información implícita) y se han trasvasado

${ }^{10}$ A lo largo del poema se aprecia el tópico horaciano del beatus ille con el que se ensalza la vida sencilla del campo en contraposición a las contiendas de la vida urbana dieciochesca. 
mediante pistas comunicativas y efectos cognitivos adecuados que acotan, por medio de su maximización, las suposiciones del receptor del texto meta. Por tanto, se reduce el esfuerzo mental del lector para lograr la interpretación del autor de la obra. De forma semejante, se ha mantenido la fidelidad en lo relativo a la semejanza interpretativa, en cuanto a que se ha pretendido trasladar representaciones mentales semejantes, salvando ciertas distancias en el enunciado.

En la estrofa decimocuarta, la voz poética introduce la dialéctica del outsider aldeano, al cual se le ha privado de su evolución como ser completo al no contribuir con el progreso ni con el devenir de la historia de la nación inglesa. Y ello pese a la posibilidad de que la fortuna hubiera podido coronarlo con los laureles del éxito, lo que ineludiblemente lo reduce a la marginación social. En este cuarteto se hace una loa del talento no reconocido de los campesinos olvidados. Como mensaje implícito, este se ha trasladado con un matiz de metáforas (la delicada flor o la lustrosa piedra preciosa que habita páramos aislados o insondables grutas oceánicas, lejos de las contiendas y los tumultos de la urbe), a modo de pistas comunicativas que obedecen al género poético, las cuales producen una serie de efectos que ayudan al lector de la cultura meta a inferir la información implícita del estímulo ostensivo verbal con el mínimo esfuerzo de procesamiento mental:

Full many a gem of purest ray serene The dark unfathom'd caves of ocean bear;

Full many a flower is born to blush unseen,

And waste its sweetness on the desert air $^{11}$.

(Th. Gray, ibidem, vv. 53-56).

Con el objeto de lograr la semejanza interpretativa y de trasvasar el mensaje críptico de acuerdo con el principio de fidelidad y el principio cognitivo de Relevancia, insta señalar que la pista comunicativa referente a la ortotipografía se ha mantenido, esto es, el signo (;) cierra la idea que se expone en cada una de las dos partes en las que se divide el cuarteto. Este aparece como indicador de una enumeración de referentes distintos (las piedras preciosas, las grutas, las flores y el páramo) con los que se expresa un mensaje común: lo que pudo ser y no pudo materializarse, rasgo distintivo de la clase campesina. Asimismo, el efecto cognitivo de la figura

\footnotetext{
${ }^{11}$ La comparación de las piedras preciosas y las flores parece ser un préstamo del «poeta de la noche» Edward Young, "Such blessings Nature pours, / O'verstock'd mankind enjoy but half her stores; / In distant wilds, by humane yes unseen, / She rears her flow'rs, and spreads velvet green: / Pure gurgling rills the lonely desert trace, / And waste their music on the savage race" (Satire V, "On Women").
} 
retórica de la estructura paralela entre el verso primero y el tercero full many a gem y full many a flower forja este punto de unión mediante su efecto repetitivo y de incidencia en la steresis aristotélica.

5a) Full many a gem of purest ray serene

$5 b)$ Muchas piedras preciosas del más puro destello

6a) The dark unfathom'd caves of ocean bear;

$6 b)$ las insondables grutas del océano encierran;

En la primera parte de la estrofa, los sintagmas nominales gem of purest ray serene y dark unfathom'd caves of ocean, que actúan como metáforas, se han trasvasado como «piedras preciosas del más puro destello» e «insondables grutas del océano», de las que se infiere el enardecimiento de esta clase social apartada y el fervor por el estado primigenio de concordia discors que la gobierna, inmaculado y prístino. La gema, como piedra preciosa, simboliza la perfección, con la que se asocia al campesino. Sin embargo, esta virtud está envuelta por la oscuridad, es decir, por la alienación social.

La otredad se implica por medio de referentes naturales de los que emanan un efecto sombrío, melancólico y de absoluta lejanía, «las grutas del océano». Este sentido se enriquece con la adición de que el desplazamiento en el espacio topográfico revela un matiz temporal mediante el lexema adjetival dark unfathom'd. Se ha suprimido el adjetivo intensificador «negras» u "oscuras», ya que la palabra «insondable» nos sugiere esta cualidad natural; la profundidad infinita es tenebrosa. La gloria del pasado de la Edad de Oro inglesa es irrecuperable y debe amoldarse al tiempo presente, cargado de caos enmascarado. El verbo bear («encerrar»), que acompaña a las grutas, refuerza el efecto de opresión que de estas, cuales cárceles o renegridas cortes, oprimen y encadenan al vulgo.

7a) Full many a flower is born to blush unseen,

7b) muchas flores germinan y no son contempladas,

8a) And waste its sweetness on the desert air.

8b) perdiendo su fragancia en los vientos del páramo.

En la segunda parte del cuarteto, la nobleza de espíritu, única riqueza que se concentra en la flor, se lee como metáfora de la que se infiere la vida primaveral y la posibilidad de la existencia del aldeano. Esta flor sin fragancia nos brinda del efecto poético de humildad y delicadeza con la 
imagen neoplatónica de la textura de los pétalos y su aroma (ánima). No obstante, los lexemas unseen, waste y el grupo preposicional on the desert air, que han sido vertidos como «no son contempladas», «perdiendo» $y$ «en los vientos del páramo» respectivamente, aportan un valor o efecto pesimista que niega la posibilidad de que se reconozca la existencia de la clase campesina.

Se ha realizado, pues, un cambio referencial, dado que el paisaje más acorde con el cuadro campestre inglés es el páramo, de condiciones hostiles similares a las del desierto, sobre todo, por la infertilidad del suelo y las frías temperaturas nocturnas. Así pues, la metáfora del páramo junto con la de los vientos (la clase social privilegiada) implica, al igual que las grutas del océano, ese lugar abandonado que evoca en nuestra mente un efecto lúgubre, de pesadumbre y de empatía, en el que la dialéctica de la inexistencia es infranqueable y la recuperación del pasado inalcanzable.

La estrofa vigésimo sexta prosigue con el relato de la vida de un joven aldeano, narrada por un campesino canoso. El cuarteto continúa la metáfora del viaje figurativo existencial al que se había dado forma con las imágenes del «Sol» y de los «prados del cerro» de los versos precedentes y que alcanza su cénit con el mediodía. La madurez del zagal errabundo se hace tangible con la reveladora imagen del sol en al mediodía, así como también con el arroyuelo, que instiga a esta figura meditabunda a contemplar su destino, el sino de los de su comunidad y el del hombre como ser subyugado a la decadencia y a la mutabilidad de su armazón material:

There, at the foot of yonder nodding beech, That wreathes its old fantastic roots so high,

His listless length, at noontide, would he stretch,

And pore upon the brook that bubbles by.

(Th. Gray, ibidem, vv. 101-104).

La serie de imágenes nodding beech, listless length y brook que conforma la interpretación implícita tiñe el cuarteto con un efecto melancólico. En este sentido se describe al muchacho, con quien los elementos naturales comulgan, afectado por el mal de la melancolía, definido por el timor mortis y la tristitia (tristeza), que normalmente va acompañada por física acedia (apatía).

Como alicientes descuellan el tædium vitæ (tedio de la vida), la inclinación por la soledad y el retiro en la Naturaleza, en una estampa resplandeciente por su derredor idílico (Iocus amœnus y beatus ille) que hacen de la enfermedad melancólica un estado del que emana el deleite para los sentidos, la elevación de las facultades espirituales y la genialidad. Mas sin embargo, la experiencia agradable de la melancolía se transforma en un profundo temor, descontento y pesadumbre, hasta el punto en el que 
el meditabundo se auto circunscribe en una atmósfera pesimista de la que es víctima, sucumbiendo ante la muerte.

El mensaje implícito de la estrofa original se ha trasvasado siguiendo el principio cognitivo de Relevancia y la semejanza interpretativa, por lo que se ha trasladado una maximización de efectos cognitivos y pistas comunicativas similares. Los versos del texto meta evocan una experiencia poética de melancolía agridulce, puesto que se emplea el marco natural del locus amœnus que se entremezcla con un cariz sombrío que incita al joven a la contemplación lúgubre causada por el timor mortis y la decadencia de la vida terrenal, culmen de su breve periplo.

En lo que respecta a las imágenes metafóricas, se destacan nodding beech, listless length y brook that bubbles by, que se han traducido como «haya combada», «recostarse lánguido» y «el arroyo que cerca gorgotea», sintagmas del primer, tercer y cuarto verso. De igual modo, estas metáforas se manifiestan como aliteraciones que, lamentablemente, se han perdido como efectos en la versión traducida, ya que sería imposible encontrar semejanza entre los fonemas de las dos lenguas. En consecuencia, de la repetición del sonido líquido lateral /I/ en el verso listless length y at noontide, se desprende un efecto poético de tranquilidad que sintoniza con la calma del locus y el estado melancólico del joven aldeano. Por añadidura, la aliteración del fonema bilabial /b/ con the brook that bubbles produce un efecto que emula la meditación y el fluir lento del agua del arroyo:

9a) There, at the foot of yonder nodding beech,

9b) Allí, al pie de aquella lejana haya combada,

En primer lugar, el lexema beech («haya») se lee como símbolo de la mutabilidad y de la muerte, puesto que en la mitología clásica este árbol se asocia con Hades (dios griego del inframundo y de la defunción). Es reseñable, además, el lexema adjetival nodding («combada») que modifica a este tipo de flora mortuoria (locus eremus), ya que con su forma inclinada comulga con el estado físico y espiritual del zagal recostado, listless length, at noontide, would he stretch, junto al arroyo y a la sombra del haya, espejo de la meditación sombría y de la aproximación de la muerte:

10a) That wreathes its old fantastic roots so high,

$10 b)$ que retuerce sus viejas raíces a lo alto,

A la metáfora del haya se le añade una connotación positiva al relacionarse con la diosa griega Cibeles y la naturaleza perenne y resistente de sus hojas y corteza. Así pues, el haya simboliza la inmortalidad. Este valor añadido se plasma en el sintagma adjetival old fantastic roots so high, 
que se ha trasladado a la lengua meta como «viejas raíces a lo alto». De todo ello se colige la implicatura de la meditación melancólica del joven sobre la fugacidad de la vida del hombre, que se contrapone al eterno ciclo de la Naturaleza. Esta reflexión en soledad representa la madurez del viaje de la vida que se pone de manifiesto con la metáfora de las tranquilas aguas del arroyo que gorgotea y con el estado melancólico del muchacho errático:

11a) And pore upon the brook that bubbles by.

$11 b)$ contemplando el arroyo que cerca gorgotea.

En el último verso, de la metáfora del arroyo que simboliza el fluir de la vida y la pureza y que siempre aparece en un escenario natural idílico (locus amœnus), se deduce la implicatura de la idiosincrasia efímera del hombre frente a la inmortalidad de la Naturaleza, pese a la desembocadura del riachuelo en el mar. Las aguas claras se leen como el espéculo de la realidad sombría que conoce el joven aldeano mediante la contemplación. Este sentido inferido se enriquece con la idea de que el agua cristalina es sinónimo de la pureza del alma, la esencia humilde del campesino que habita el retiro del locus campestre frente a la decadencia de la urbe. La noción neoplatónica que se atribuye al arroyo anticipa la idea de la eternidad del alma del dogma cristiano que se plasma en el epitafio. Según esto, el ciclo natural pierde fuerza con la victoria de la resurrección espiritual, que eleva al alma inmaculada del joven campesino.

\section{CONCLUSIONES}

Si se examina con detalle el poema (estímulo ostensivo verbal), discurso de estilo literario henchido de efectos cognitivos poéticos, con un telón de fondo referencial, cultural y lingüístico concreto, de su lectura se puede colegir que, como acto de comunicación ostensivo e inferencial, el autor del texto origen muestra su mensaje de forma relativamente encriptada. Su traducción (estímulo ostensivo verbal meta), concretamente la traducción indirecta, es una lectura e interpretación del original, es decir, un acto de comunicación secundaria en el que se pretende guardar la misma pretensión de Relevancia en el texto meta con respecto al original.

Puesto que el poeta comunica mensajes con la intención de ser relevante, esperando que lo sea igualmente para el lector del texto de partida, hemos procurado que la traducción mantenga cierta semejanza, relevante en su interpretación, para el lector meta, como lo hizo el texto fuente para el receptor de la lengua origen, conservando el mensaje implicado del poema inglés y acotando la distancia entre los diferentes 
contextos cognitivos o realidades mentales del poeta y del destinatario del texto de llegada.

Según la Teoría de la Relevancia (Sperber and Wilson 1986; 1995), deducir las suposiciones contextuales óptimamente relevantes que vela el emisor en el estímulo ostensivo verbal no debe suponer un incremento de esfuerzo mental a cargo del receptor meta, de lo contrario, el mensaje dejaría de ser óptimamente relevante, de modo que llegaría a ser irrelevante en muchos casos. Es por ello por lo que se ha optado por suplir al receptor del texto meta con una maximización de efectos cognitivos que disminuyan el esfuerzo de procesamiento mental y ayuden al destinatario a inferir las suposiciones contextuales implicadas de las que se deduciría la información implícita. Con este proceder, se ha tratado de resarcir la discrepancia que se origina del factor lingüístico y cultural para hacer que tanto el contexto cognitivo del autor como el del lector del texto de llegada sean mutuamente manifiestos.

Ya que la traducción de "Elegy Written in a Country Churchyard" se ha abordado mediante una perspectiva interpretativa de la lengua, esta se ciñe al principio de semejanza interpretativa. Se trata de representar el pensamiento, suposiciones cognitivas o información implícita que el autor ha pretendido. Por tanto, ¿cómo se llega al trasvase de la información implícita del poema que se expresa mediante implicaturas? En el texto de partida, "Elegy Written in a Country Churchyard", debido al género literario en el que se encuadra y al estilo poético propio de la lírica, el poeta se sirve de una plétora de pistas comunicativas (propiedades textuales y estilísticas) como las figuras literarias que, aunque generan multitud de efectos poéticos, implicaturas débiles y nuevas suposiciones contextuales, son orientativas en cuanto a la producción de un incremento de efectos cognitivos que confirman o niegan las conclusiones relevantes del lector del texto meta. Por ende, la traducción del poema debe cimentarse en aquellas pistas comunicativas del original, modificándose hasta cierto punto, dadas las diferencias lingüístico-culturales, para lograr la semejanza interpretativa, el menor esfuerzo de procesamiento y la comunicación efectiva del mensaje implícito al lector del texto de llegada.

\section{REFERENCIAS BIBLIOGRÁFÍCAS}

BLACK, Joseph, "Thomas Gray." En: The Broadview Anthology of British Literature. Toronto (Canada): Broadview Press, 2011, pp. 1542-1543.

DAHLGREN, Marta, "Preciser that we are: Emily Dickinson's poems in translation. A study in literary pragmatics." En: Journal of Pragmatics, 37, 2005, pp. 1081-1107.

DANTE, Alighieri, The Purgatorio. Trad. Charles Wright Ichabod. London: Longman, Orme, Brown, Green, and Longman, 1845. 
ESCANDELL, María Victoria, "La noción de estilo en la teoría de la relevancia". En: Lingüística y estilística de textos. Amsterdam-Atlanta: Rodopi, 1994, pp. 55-64.

GarcíA-LORCA, Federico, Canciones: selección. Santiago de Chile: Andrés Bello, 1996.

GRAY, Thomas, "Elegy Written in a Country Churchyard." London: John van Voorst, 1834.

GUTT, Ernst-August, "Translation and Relevance." En: UCL Working Papers in Linguistics, 1, 1989, pp. 75-95.

— , "A Theoretical Account of Translation-Without a Translation Theory." En: Target: International Journal of Translation Studies, 2, 1990, pp. 135-164.

-, "On the Nature and Treatment of Implicit Information in Literary Translation: A Relevance-Theoretic Perspective." En: International Journal of Translation Studies, 8, 1996, pp. 241-256.

_- "Textual Properties, Communicative Clues and the Translator." En: M. Pilar Navarro-Errasti, Rosa Lores-Sanz, Silvia Murillo-Ornat and Carmina Buesa-Gómez (eds.). Transcultural Communication: Pragmalinguistic Aspects. Zaragoza: Anubar, 2000, pp. 161-170.

INGARDEN, Roman, The Cognition of Literary Work of Art. Evanston: Northwestern University Press, 1973.

LARSON, M. L., Meaning-based Translation: A Guide to Cross-Language Equivalence. New York: University Press of America, 1984.

LONSDALE, Roger, Thomas Gray, William Collins, Oliver Goldsmith. London and Harlow: Longmans, 1969.

LÓPEZ-FOLGADO, Vicente, “'Design', interpretación y traducción de un poema de Robert Frost". En: Eva Parra y Ángeles García (eds.). Traducción, mediación, adaptación: reflexiones en torno al proceso de comunicación entre culturas. Berlín: Fran \& Timme GmbH, 2013, 93106.

—-, Translation of "Elegy Written in a Country Churchyard" by Thomas Gray." En: Cadernos Eborenses, 1, 2009, pp. 123-159.

—, "Traducción y Relevancia: ¿Qué quiere decir 'semejanza interpretativa' en traducción?". En: Nobel Perdu (ed.). Cambio de Dimensiones en Traducción y Comunicación. Almería: Editorial Universidad de Almería, 2010, pp. 47-72.

MEY, Jacob, When Voices Clash: A Study in Literary Pragmatics. Berlin and New York: Mouton de Gruyter, 2010.

NIDA, Eugene; TABER, Charles, The Theory and Practice of Translation. Leiden: E. J. Brill, 1969.

PILKInTON, Adrian, Poetic Effects. Amsterdam: John Benjamins, 2000. 
SMITH, Kevin, "Translation as Secondary Communication. The Relevance Theory Perspective of Ernst-August Gutt." En: Acta Theologica Supplementum, 2, 2002, pp. 107-117.

Sperber, Dan; WILSON, Deirdre, Relevance: Communication and Cognition. London: Basil Blackwell, 1991.

—- "Rhetoric and Relevance." En: John B. Bender and David E. Wellbery (eds.). The Ends of Rhetoric: History, Theory, Practice. Standford: Standford University Press, 1990, pp. 140-155.

VERGARA, Gloria, "Los valores artísticos y estéticos como fundamento ontológico del mundo literario". En: Revista de Humanidades, 13, 2002, pp. 71-83.

VILLA-JIMÉNEZ, Rosalía; LóPEZ-FOLGADO, Vicente, "Don Juan de Escóiquiz's "Elegy Written in a Country Churchyard." En: Ma Mar Rivas \& Carmen Balbuena (eds.). Cultural Aspects of Translation. Tübingen: Narr Verlag, 2013. pp. 237-256.

YounG, Edward, "Satire V. On Women." The Poetical Works of Milton, Young, Gray, Beattie, and Collins. Philadelphia: John Grigg, 1836.

ZHONGGANG, Sang, "A Relevance Theory Perspective on Translating the Implicit Information in Literary Texts." En: Journal of Translation, 2: 2, 2006, pp. 43-60. 